\title{
Reimplante intencional en diente geminado con lesión endoperio tipo IV. Reporte de
} caso

\section{Intentional replantation gemina injured in tooth type IV endoperio. Case report}

Rodríguez Rodríguez RS*, Gaitan Ibarra G**, Díaz Caballero A***

\section{RESUMEN}

En los dientes con geminación y lesiones periapicales no resueltas después de un tratamiento endodóntico se debe pensar no solo en un diagnostico endodóntico sino también periodontal, ya que estos dientes en el intento de separación pueden presentar surcos o fisuras que van desde el borde incisal hasta la raíz convirtiéndose en un canal de comunicación entre la zona apical y la cavidad oral.

Para realizar el plan de tratamiento se debe tener en cuenta: sintomatología persistente, posterior a la terapia endodóntica, persistencia de fístula, lesión periapical de gran tamaño, bolsa periodontal, anatomía radicular palatina del órgano dentario (presunto canal palatino), y que la anatomía del diente sea favorable para realizar el procedimiento.

La extracción y reimplante intencional es el tratamiento indicado en casos donde el tratamiento endodóntico fracasa y por la anomalía dental, la cirugía periapical también fallaría porque solo se eliminaría la lesión momentáneamente más no la que lo causa que es la comunicación entre la cavidad oral y la zona apical.

Sin embargo, se sabe que esta opción de tratamiento puede traer riesgos y beneficios, incluyendo pérdida del diente o una posible anquilosis y con una de tasa de éxito del $42,9 \%$.

El presenta caso clínico describe la extracción y reimplante intencional en un diente geminado con una lesión periapical persistente de origen periodontal, con sintomatología y fístula, posterior a tratamiento endodóntico complejo, su evolución y éxito.

Palabras clave: Anomalías dentarias, endodoncia, reimplante dental, dientes fusionados, lesiones endoperiodontales (Decs Bireme).

\section{SUMMARY}

In teeth with gemination and unresolved periapical lesions after endodontic treatment we must think not only in diagnosis but also periodontal endodontic, as these teeth in the attempt of separation may have grooves or cracks that go from the incisal edge to root becoming a channel of communication between the apical and oral cavity.

To make the treatment plan should take into account: persistent symptoms, after endodontic therapy, persistent fistula, large periapical lesions, periodontal pocket, root anatomy of the tooth organ palate (palatine canal alleged) and that the anatomy tooth is favorable to perform the procedure.

* Odontóloga Universidad de Cartagena. Residente Postgrado de Endodoncia Universidad de Cartagena. Odontólogo Universidad de Cartagena. Especialista en Endodoncia Universidad de Cartagena. Especialista en gerencia en servicios de salud y auditoría en servicio de salud.

*** Odontólogo Universidad de Cartagena. Especialista en Periodoncia Universidad Javeriana. Magister en educación Universidad del Norte. Candidato a Doctor en Ciencias Biomédicas Universidad de Cartagena. Profesor titular Universidad de Cartagena. Director Grupo de Investigaciones GITOUC. 
The extraction and intentional replantation is the treatment in cases where the endodontic treatment fails and the anomaly dental periapical surgery also fail because only temporarily remove the lesion but not the cause it is the communication between the oral cavity and apical area.

However, it is known that this treatment option can have risks and benefits, including tooth loss or possible ankylosis and with a success rate of $42.9 \%$.

The present case report describes the extraction and intentional replantation geminate tooth with a persistent periapical lesion of periodontal origin, with symptoms and fistula, after endodontic treatment complex, its evolution and success.

Key words: Tooth abnormality, fused teeth, endodontics, Tooth Replantation (MeSH database).

Fecha de recepción: 5 de abril de 2011 .

Aceptado para publicación: 11 de mayo de 2011.

Rodríguez Rodríguez RS, Gaitan Ibarra G, Díaz Caballero A. Reimplante intencional en diente geminado con lesión endoperio tipo IV. Reporte de caso. Av. Odontoestomatol 2012; 28 (5): 233-238.

\section{INTRODUCCIÓN}

El reimplante intencional es definido como la remoción intencional del diente y su reinserción dentro del alvéolo después de la manipulación endodóntica. Este procedimiento es recomendado en situaciones donde el tratamiento convencional es difícil o imposible de realizar y en donde el abordaje quirúrgico es necesario. Es decir la exodoncia intencional de un diente y su reinserción en el alvéolo, previa apicectomía o apicectomía con obturación retrógrada. Este tratamiento se debe considerar como el último recurso para mantener un diente en boca. (1)

El reimplante intencional es una técnica realizada desde hace 10 siglos y fue utilizada inicialmente en odontalgias. El primero en referenciar esta técnica fue Abulcais en el siglo V D.C., luego fue recomendada por Pare en 1561, por Pierre Fauchard en 1712 y en Rusia por Philipp Pfaff, quien la combinaba con la resección del ápice radicular y posterior obturación con cera, en casos de dientes muy largos. En 1966 el Dr. Louis L. Grossman define reimplantación como "la remoción intencional de un diente y su casi inmediata reimplantación, con el objeto de obturar los conductos desde apical mientras el diente está fuera de su alvéolo". Éste no es un procedimiento nuevo, se está realizando desde 1950 y existe evidencia de reportes por Grossman de una tasa de éxito del $80 \%$ desde 2 a 11 años después de la reimplantación (2, 3).

Las técnicas modernas de reimplantación están basadas en los conceptos biológicos de la importancia del mantenimiento de la viabilidad del ligamento periodontal. La duración del procedimiento es limitado a la extensión del tiempo en que las células permanecen viables ex situ. Los análisis histológicos de las técnicas recientes de reimplantación en animales muestran sólo pequeñas áreas de microanquilosis (4).

Antes de realizar un reimplante intencional se deben tener en cuenta los signos y síntomas del paciente, anatomía del diente, la condición general de la dentición, la oclusión y la función masticatoria. Los dientes después del reimplante deben ser restaurados a una buena función oclusal, ya que la oclusión traumática puede ocasionar el fracaso del tratamiento. Además se debe analizar para tener un mejor pronóstico, el estado periodontal, las posibilidades de restaurar el diente, el hueso (5).

En dientes geminados en su intención de separarse forman canales de comunicación entre la cavidad oral y el periodonto originando lesiones endoperiodontales, los problemas pulpares y periodontales son causantes de más de $50 \%$ de la mortalidad dentaria 
y a menudo difíciles de diagnosticar, pues las sustancias tóxicas de la pulpa pueden iniciar los defectos periodontales y viceversa, a través del periápice, túbulos dentinarios, conductos laterales o accesorios y otras alteraciones dentarias. El pronóstico dependerá de diversos factores, tales como la causa primaria y la respuesta del huésped, de modo que el tratamiento es de suma importancia y gran interés, cuyo orden estará determinado por el origen primario $(6,7)$.

Las lesiones endoperiodontales constituyen un grupo de lesiones de naturaleza inflamatoria que comprometen simultáneamente a las estructuras del periodonto de inserción y a la pulpa dentaria. Para el diagnóstico se evalúan las dos áreas por separado y luego en conjunto, a través de signos y síntomas como el dolor por el compromiso pulpar, estudio radiográfico para ver el grado de avance y la existencia de conductos laterales, examen de vitalidad pulpar, sondaje periodontal y evaluación clínica (8).

Las lesiones endoperiodontales se clasifican en:

- Tipo I: Lesión endodóntica pura en donde hay un drenaje a través del foramen, conductos accesorios, etc. empezando a comprometer la zona. Si esta contaminación continúa puede haber acumulación de depósitos o placa bacteriana, comprometiendo el ligamento periodontal. El tratamiento es endodóntico puro.

- Tipo II: Lesión de origen endodóntico con compromiso periodontal secundario. El tratamiento es pulpar y periodontal.

- Tipo III: Lesión periodontal pura, en donde el grado de avance no ha llegado a comprometer la pulpa. El tratamiento es periodontal puro.

- Tipo IV: Lesión periodontal primaria con compromiso pulpar secundario. El tratamiento es pulpar y periodontal.

- Tipo V: Lesión pulpo-periodontal verdadera o lesión combinada. Son 2 lesiones que partieron separadamente pero por su avance se unieron. El tratamiento es pulpar y periodontal.

En la lesión endoperiodontal propiamente la pulpa comprometida debe estar desvitalizada o con síntomas de lesión pulpar, debe haber pérdida de inserción periodontal desde el margen gingival hasta el ápice o conducto lateral comprometido, tanto la te- rapia periodontal como la endodóntica son necesarias con el fin de resolver la lesión (8).

\section{PRESENTACIÓN DE CASO CLINICO}

Paciente masculino de 27 años sin antecedentes médicos de importancia. Se le realizó endodoncia por un diagnostico pulpar de periodontitis apical crónica supurativa en diente incisivo lateral superior derecho con geminación y raspado y alisado radicular a campo cerrado por un diagnostico periodontal de periodontitis crónica avanzada; con pronóstico reservado. Se realizó endodoncia con técnica rotatoria protaper y convencional, obturación de cuatro conductos, dos con conos únicos y dos con conos de gutapercha con técnica lateral y vertical, en todos los conductos se utilizó cemento resinoso. Se citó al mes para seguimiento, con disminución del dolor pero persistencia de la fístula. Al control de cuatro meses se observó dolor a la percusión, fístula persistente, persistencia de la lesión (Fig. 1). Se diagnostico: "Periodontitis apical Crónica supurativa" o "lesión periodontal primaria con compromiso endodóntico secundario", con un pronóstico reservado. Para el plan de tratamiento se tuvieron en cuenta las siguientes consideraciones:

- Sintomatología persistente, posterior a la terapia endodóntica.

- Persistencia de fístula vestibular.

- Lesión periapical de gran tamaño.

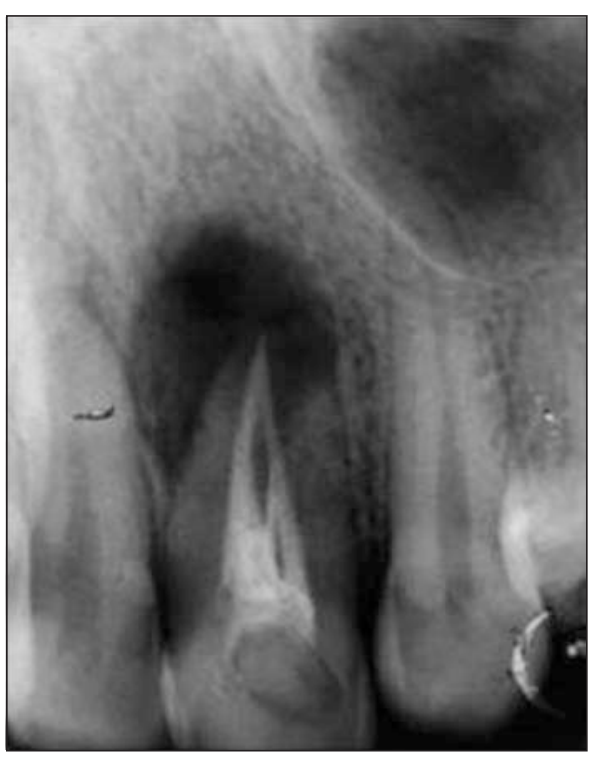

Fig. 1. Radiografía de control-proyección mesializada. 
- Gran bolsa palatina con sondaje de $7 \mathrm{~mm}$.

- Anatomía radicular palatina del órgano dentario (presunto canal palatino).

- Anatomía favorable para realizar el procedimiento.

El tratamiento indicado fue reimplante intencional en diente incisivo lateral superior derecho.

El procedimiento quirúrgico fue de la siguiente manera:

El paciente realiza enjuagues bucales con clorhexidina y se le limpia extra oralmente con solución yodada, se coloca anestesia troncular del nervio infraorbitario y nasopalatino, sondaje palatino presentando bolsa periodontal de $9 \mathrm{~mm}$ se toma fistulografía, se hace la exodoncia con palpación firme de la tabla ósea, movimientos de luxación firmes y poco profundos para disminuir el daño periodontal, se sujeta el diente con el fórceps sin excesiva fuerza de compresión y teniendo control digital sobre las tablas óseas, en el diente extraído se observa el canal palatino con abundante tejido de granulación (Fig. 2) se retira el tejido de granulación y se hace un tallado ligeramente retentivo con pieza de alta velocidad y fresa redonda pequeña de diamante, apicectomía y obturación retrógrada con pieza de alta velocidad y se obtura tanto el canal palatino como la obturación retrógrada con ionómero de vidrio (Fig. 3) se curetea

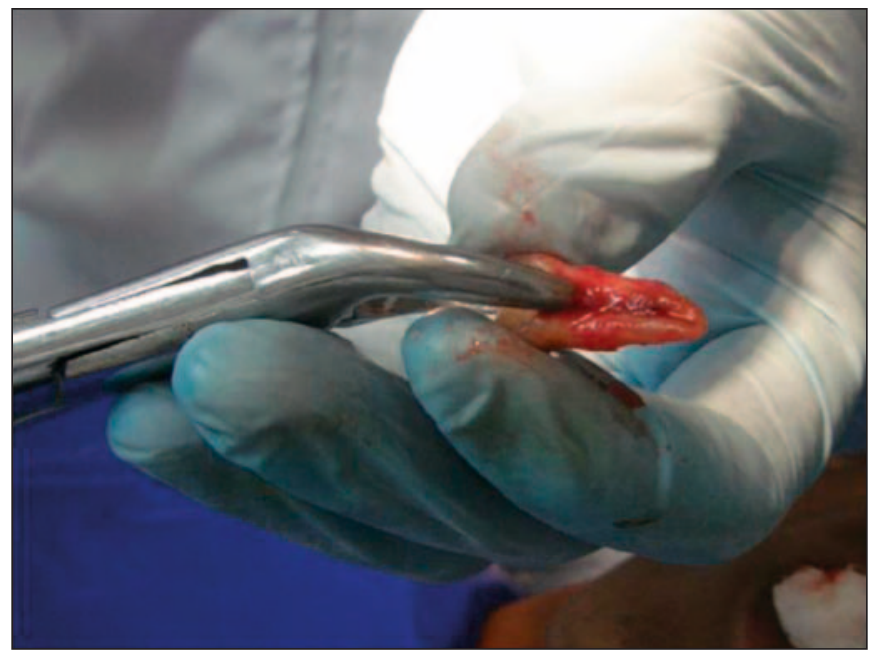

Fig. 2. Diente extraído, observe canal palatino con abundante tejido de granulación.

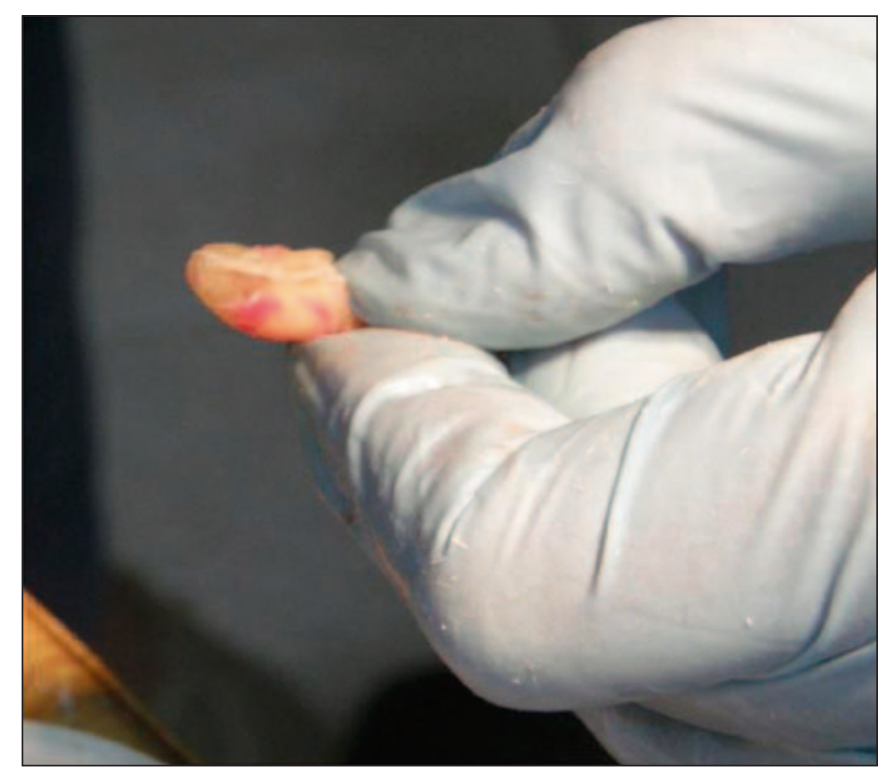

Fig. 3. Obturación del canal palatino con ionómero de vidrio de foto.

y se raspa la lesión principalmente en el fondo del alveolo, se irriga con solución salina y de doxiciclina, se coloca y ajusta el diente dentro del alveolo con presión digital, se coloca férula semirrígida desde órgano dentario 14 a 23, se sutura las papilas, se le aplica cianoacrilato en el borde gingival. La duración del diente fuera del alveolo fue de 7 minutos y medio.

Se le hace un control a los 2 meses y no hay presencia de la fístula ni sintomatología, disminución de la lesión radiográficamente y el sondaje palatino fue de $4 \mathrm{~mm}$ (Fig. 4). Al control de los 8 meses se observa reparación de la lesión (Fig. 5).

\section{DISCUSIÓN}

Es importante saber que las lesiones endoperiodontales verdaderas son raras de encontrar y se presentan principalmente en diente fracturado verticalmente o de un diente con un surco gingivopalatino de desarrollo (generalmente en laterales superiores) como en este caso. En estos casos el pronóstico es reservado aún con tratamiento de endodóntico y periodontal excelentes

En el manejo de las lesiones endoperiodontales, varios estudios apoyan realizar el tratamiento de 


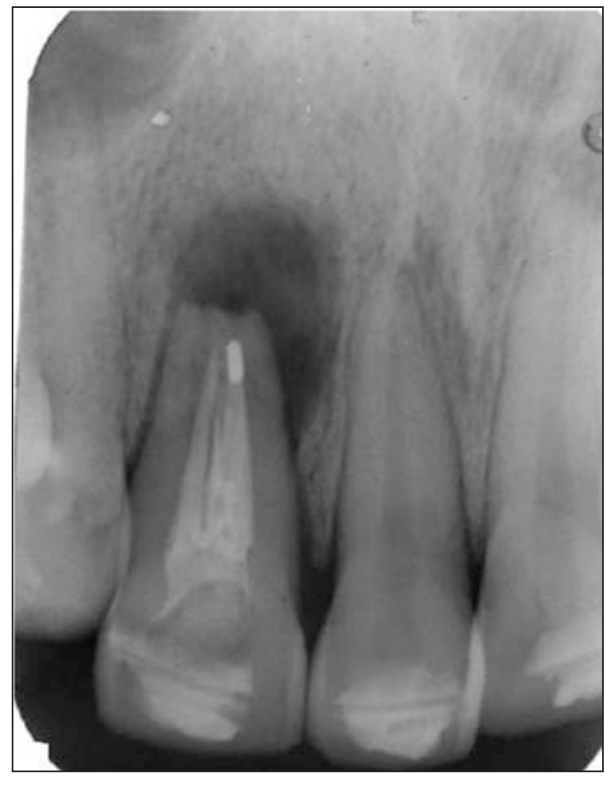

Fig. 4. Radiografía de control a los 2 meses.

conductos previo al tratamiento periodontal. Es esencial un periodo de observación de al menos 1 mes de evolución para permitir el potencial de regeneración tisular después del tratamiento de conductos radiculares (9).

Esta estrategia es ventajosa por tres razones; primero, el espacio endodóntico puede ser desinfectado

Fig. 5. Radiografía de control a los 8 meses con reparación de la lesión. mediante el tratamiento endodóntico, confinando la infección e irritantes bacterianos al defecto periodontal mediante el sellado del camino de comunicación entre la pulpa y el periodonto. La segunda razón consiste en que el raspado y alisado radicular puede interferir en el potencial de reinserción debido a que probablemente hayan fibras del ligamento periodontal insertadas e intactas que presentan potencial de regeneración del aparato de inserción tras el tratamiento de conductos. Y por último, si el tratamiento periodontal se realizara previo al endodóntico, la cicatrización periodontal puede comprometerse por los irritantes derivados del sistema de conductos radiculares $(9,10)$.

Existe controversia acerca del periodo observacional tras el tratamiento de conductos. Se ha sugerido un periodo de 3 meses, en cambio otros autores sugieren de $2-3$ meses, o de $1-2$ meses $(5,8,10)$

En el presente caso además del tiempo de observación luego del tratamiento endodóntico se tiene que tener en cuenta el diagnostico de la alteración anatómica, diagnostico de la patología pulpar y periapical, el tratamiento ideal (ciapicectomía y enucleación? o creimplante intencional y curetaje alveolar?) y el material de retro obturación.

\section{CONCLUSIÓN}

La endodoncia, así como la periodoncia, a menudo se consideran entidades separadas, aunque clínicamente están estrechamente relacionadas, lo cual debe influenciar nuestro diagnóstico y tratamiento. No existe duda que la inflamación o la necrosis del tejido pulpar afectarán a los tejidos periodontales y viceversa. La comunicación entre los tejidos periodontales y pulpares puede producirse a través del foramen apical, conductos laterales, fracturas radiculares o perforaciones o por variaciones anatómicas. De tal manera, el diagnóstico de dichas afecciones es vital para llevar a cabo un acertado tratamiento y mejorar su pronóstico con el fin de la conservación del órgano dentario para que en el paciente no se afecte la estética y funcionalidad.

La enfermedad periodontal es la principal contraindicación para la reimplantación intencional. 
El reimplante dental está indicado en los casos en que se hace imposible o riesgo de un procedimiento endodóntico convencional o quirúrgico. El tiempo extra oral y el mantener las raíces dentales húmedas son aspectos fundamentales durante el procedimiento para asegurar su éxito. El porcentaje de éxito para el reimplante dental es favorable pero no mejor que el de la cirugía endodóntica o el tratamiento de conductos convencional.

Actualmente el cemento MTA se considera el material óptimo para realizar la obturación retrógrada durante la reimplantación intencional.

Para aquellos odontólogos que creemos en la conservación de la dentición natural, el reimplante intencional puede convertirse en una herramienta para casos calificados en los cuales se haría una extracción dental.

\section{BIBLIOGRAFÍA}

1. Kratchman S. Intentional replantation. Dent Clin North Am. 1997 Jul;41(3):603-17.

2. Ross WJ. Intentional replantation: an alternative. Compend Contin Educ Dent. 1985 Nov-Dec;6 (10):734, 6-9.

3. Grossman LI. Intentional replantation of teeth. J Am Dent Assoc. 1966 May;72(5):1111-8.

4. Koenig KH, Nguyen NT, Barkhordar RA. Intentional replantation: a report of 192 cases. Gen Dent. 1988 Jul-Aug;36(4):327-31.
5. Bender IB, Rossman LE. Intentional replantation of endodontically treated teeth. Oral Surg Oral Med Oral Pathol. 1993 Nov;76(5):623-30.

6. Cohen S, Berman LH, Blanco L, Bakland L, Kim JS. A demographic analysis of vertical root fractures. J Endod. 2006 Dec;32(12):1160-3.

7. Kurihara H, Kobayashi Y, Francisco IA, Isoshima O, Nagai A, Murayama Y. A microbiological and immunological study of endodontic-periodontic lesions. J Endod. 1995 Dec;21(12):617-21.

8. Rotstein I, Simon JH. Diagnosis, prognosis and decision-making in the treatment of combined periodontal-endodontic lesions. Periodontol 2000. 2004;34:165-203.

9. Zehnder M, Gold SI, Hasselgren G. Pathologic interactions in pulpal and periodontal tissues. $\mathrm{J}$ Clin Periodontol. 2002 Aug;29(8):663-71.

10. Lustig JP, Tamse A, Fuss Z. Pattern of bone resorption in vertically fractured, endodontically treated teeth. Oral Surg Oral Med Oral Pathol Oral Radiol Endod. 2000 Aug;90(2):224-7.

\section{CORRESPONDENCIA}

Rubby Rodríguez Rodríguez

Campus de la salud. Zaragocilla.

Cartagena de Indias, Bolívar, Colombia

Correo electrónico: rubbysofia@yahoo.com, gaitanibarragaston@hotmail.com, adiazc1@unicartagena.edu.co 